\title{
Evaluation of Lightning Impulse Test by Frequency Response Analysis
}

\author{
Baudilio Valecillos, and Jorge Ramirez, Senior Member, IEEE
}

\begin{abstract}
In this work are presented the basis for improving the interpretation of transformer lightning impulse test and the development of a graphical user interface system, which allows comparisons of time domain data and frequency response. The frequency response is obtained from deconvolution of voltage and neutral current records. A quantitative comparison of frequency response is performed using the techniques applied to displacement detection through Frequency Response Analysis, such as correlation and spectral deviation. The system is implemented using 8 bit digitizers to acquire the voltage and neutral current records. The quantization error and reliability of the frequency response obtained is handled through the use of the coherence function and tolerance bands. The system is thoroughly tested applying a lightning impulse test to a dry type distribution transformer, simulating an inter-disc fault with a spark gap. Failure detection is confirmed.
\end{abstract}

Index Terms--Coherence Function, Frequency Response Analysis, Lightning Impulse Testing, Spectral Deviation, Tolerance Bands.

\section{INTRODUCTION}

$\mathrm{L}_{\mathrm{r}}^{\mathrm{i}}$ ightning impulse testing of power transformer is a standard practice. It characterizes the time-voltage behaviour of the transformer insulation against an specific waveform [1]. Due to the transient characteristic of the phenomena an oscillating voltage distribution occurs and this can produce a voltage to ground of up to twice the magnitude of the applied wave [2]. During the application of impulse test specific waveforms of different magnitude are applied to each winding, voltage and neutral current traces are recorded. Qualitative comparison of the acquired waveforms is the main criteria to establish the test results [3], [4]. Pass-fail criteria have been developed over years of experience; even though, this criterion is qualitative and relies on the experience of the expert applying the test. This often results in controversy between the manufacturer and testing facility expert. Obtaining the transfer function of the transformer, from deconvolution of the applied voltage and neutral current oscillograph acquired during the application of the impulse test, is recommended by several authors to improve the interpretation of results [5], [6], [7]. This is so because the effect of failure is magnified in the

B. Valecillos is with the Department of Electrical Engineering University Carlos III de Madrid, 28911 Madrid Spain. (e-mail: bvalecil@ing.uc3m.es)

J. Ramirez is with the Department of Energy Conversion and Transport, Simon Bolivar University, A1080 Caracas, Venezuela. (e-mail: jramirez@usb.ve). frequency domain. The procedure is not standard.

Independently of its use as aide in lightning im pulse test interpretation, the transformer frequency domain response is used to diagnose winding deformation. Frequency Response Analysis (FRA) is an important developing technique that finds the frequency dependent impedance of the transformer and correlates its changes over time to physical deformation of the transformer windings [8]. Diagnosis using FRA is usually done by qualitative comparison of records obtained during the life of the transformer but several authors are proposing quantitative indicators such as correlation coefficient [9], tolerance bands [10] and spectral deviation [11].

The present work is an initiative to use the quantitative indicators being developed for comparison of frequency responses obtained through FRA into comparison of frequency responses obtained from lightning impulse test. The transformer frequency response is obtained instead of the transfer function making the software developed capable to model and diagnose other systems by means of frequency response, such as: surge arresters [12], transient grounding systems [13], transformer transient behaviour [14] and cable diagnosis [15].

\section{IMPULSE TESTING}

\section{A. Test interpretation}

Impulse test is applied to evaluate transformer insulation against lightning impulse discharges, is a type test for class I power and distribution transformers, a standard test for class II transformers and can be implemented using an special procedure as routine test for distribution transformers [18]. It is a well established procedure and information on application, requirements and interpretation of test results is presented in IEEE [1], [3], [19], [21] and IEC [4], [20], [23], [24] standards and guides. Several examples can be extracted from the guides [1], [23] revealing ability of failure detection based on oscillograms of the applied voltage and neutral current. Furthermore, different connection schemes are allowed that can be more sensitive to different types of failures and adapted to transformer construction [1]. Even so failures of a few shorted turns of a winding under test are very difficult to spot using the standard connection, which is, measuring the neutral current of the winding under test with all other windings connected to ground. And, since there is no previous knowledge of the type of failure that could occur during the 
test, usually the standard connection is the one used. This leads to uncertainty with respect to the pass-fail criteria of the test regarding difficult cases.

\section{B. Transfer Function Method}

Obtaining the transfer function of the transformer, from deconvolution of the applied voltage and neutral current oscillograph, acquired during the application of the impulse test, is based on the relation between impulse response (Dirac) and frequency response, that is, the Fourier transform of the impulse(Dirac) response is the frequency response [24]. Because the most common measurements acquired during impulse testing are applied voltage and neutral current the transfer function analyzed is the impedance of the winding under test with all other connections to ground. Even so another transfer functions as transferred voltage between adjacent windings may be more sensitive to some types of faults [25].

Digital records of applied voltage and neutral current are necessary to apply the Fast Fourier Transform in order to obtain the frequency response. A proper digitizer with a resolution of at least $10 \mathrm{bits}$ and $30 \mathrm{MHz}$ sampling rate must be used to ensure repeatability of the frequency response up to $2 \mathrm{MHz}$ [26], [27]. But even with a digitizer properly specified [28], there is electromagnetic noise and quantization error that will limit the upper frequency obtainable from impulse testing. This upper limit can be determined by the use of the coherence function [29], that identifies the linearity of a system by correlating the frequencies in its input and output [30]. A coherence of value equal to " 1 " ensures complete linearity of a system at a given frequency, some authors [29] indicate that the coherence should be as close to unity as possible in order to consider the frequency reliable for diagnosis, others [31] justify the use of portions of the curve that have a low coherence but advise caution.

\section{Frequency Response Analysis}

Frequency Response Analysis (FRA) has become a usual technique for diagnosing mechanical integrity of power transformers [32], and as such several application and interpretation schemes have begun to develop surrounding the technique. The frequency response can be obtained off line by frequency sweep (FRA-S) [8], it can be obtained by impulses (FRA-I) [5], or by a Chirp function [33].

The use of the Transfer Function Method is also being applied to online monitoring of power transformers. Using the transients on the electric grid to act as impulses and measuring the neutral current of the transformer [34], [35] the transfer function can be obtained. High electromagnetic interference and different frequency content of the applied impulses have led to differences appearing in the transfer function. Tolerance bands have been used to discriminate those differences so they can be identified either as failures within the transformer or noise present in the measurements [10].

In FRA the usual diagnostic method is the comparison of frequency responses obtained during the transformer operational life. Other interpretation techniques are being developed and used by utilities to diagnose deformation of transformer windings. Some of them include the use of correlation and spectral deviation between traces [36], [37]. Other advances have been done regarding the sensitivity of the methods to detect displacement and deformations of windings [38], [39], [40]. Several efforts regarding the application of neural networks to correlate the change in the frequency response and the type of the deformation have been made [9], [41]. Modeling the transformer and correlating frequency response and model changes is another approach under study [38], [42], [43].

The fact that the analysis is always performed by comparison of past and present frequency response curves of the same transformer, makes the method difficult to apply to transformers that do not have a previous measurement. The usual solution is to compare measurement between phases of the same transformer or compare measurements between two twin units [31], [44].

\section{IMPLEMENTATION}

\section{A. Hardware}

The system is implemented using a digital oscilloscope with resolution of $8 \mathrm{Bits}, 2.5 \mathrm{GHz}$ Bandwidth and 10000 samples as the data acquisition device, two toroidal transient current transformers are used to measure neutral current of the winding under test. A repetitive surge generator is used to calibrate the system. Final tests are performed using $2.4 \mathrm{MV}$ impulse generator and a damped capacitive voltage divider. Prior to the measuring phase several simulations were performed to verify the applicability of an 8 Bit digitizer. It has been shown [26] that to obtain a reliable transfer function up to $2 \mathrm{MHz}$ for a power transformer, through impulse testing, a 10 bit digitizer is need. Even so, using an 8bit digitizer with high bandwidth and sampling rate repeatability of the transfer function up to $1 \mathrm{MHz}$ can be obtained [45]. Furthermore by means of tolerance bands [10] differences between measurements can be assessed as noise or failure of the winding under test. Several test where performer to determine proper bandwidth of the transient current transformers and voltage divider used.

\section{B. Algorithm}

The frequency response is obtained using (1). The complete algorithm applied is shown in Fig. 1. Here FFT denotes the Fast Fourier Transform of the voltage and current impulses respectively. 


$$
R F=\frac{F F T(V(t))}{F F T(I(t))}
$$

A typical $10 \mu$ s per division time base is used to allow good comparison of voltage and current in time domain so application of exponential windows to the voltage and current records is necessary to avoid leakage effect due to abrupt ending of the acquired data [40]. The data is properly downsampled [7] and zeropadded [46] to increase the resolution of the obtained frequency response. Because the impulse voltage has to comply with the $1.2 / 50 \mu$ s of lightning impulse wave, the use of finite record length digitizer, and the exponential window applied; the frequency response obtained by this algorithm can not be expected to match exactly to that obtained by a frequency sweep. Instead this match will only occur in a frequency interval between $30 \mathrm{kHz}$ and the $1 \mathrm{MHz}$ limit imposed by the impulse shape and low resolution digitizer.

The upper range of frequency reliable for diagnosis is determined by the use of the coherence function calculated between several calibrating impulses using (2), as implemented in [29].

$$
C f=\frac{S x y^{2}}{S x x^{*} S y y}
$$

\section{System calibration}

The system calibration is performed using the repetitive surge generator. In Fig. 2 the frequency response of the power transformer under study is shown. The reference frequency response was obtained using the repetitive surge generator and acquiring 64 consecutive impulses using the oscilloscope averaging mode. This way the signal to noise ratio (SNR) can be improved by $18 \mathrm{~dB}$ giving a nominal SNR of $66 \mathrm{~dB}$ approximately the same obtained using a 10bit digitizer [47]. The responses obtained applying three different impulses show the repeatability of the measurement up to $500 \mathrm{kHz}$.

The coherence between the three measurements shown in Fig. 2 is plotted in Fig. 3. This reveals how at $500 \mathrm{kHz}$ there is a lump in the coherence function that indicates that this frequency is not reliable for diagnostic. This lump is due to spurious introduced by the oscilloscope.

In Fig. 4 the frequency response of the transformer having an inter disc failure modeled by a short circuit is compared to a non fault response. It can be seen that the two responses differ clearly; the most important difference in regard of diagnosis is the displacement of the resonance peak at $250 \mathrm{kHz}$. The correlation between two measurements without any fault and the correlation between non faulted and faulted test are shown in table 1. The correlation function decrease in the frequency range between $100 \mathrm{kHz}$ and $250 \mathrm{kHz}$ complement the diagnostic clearly visible as the difference in frequency response in Fig. 4.

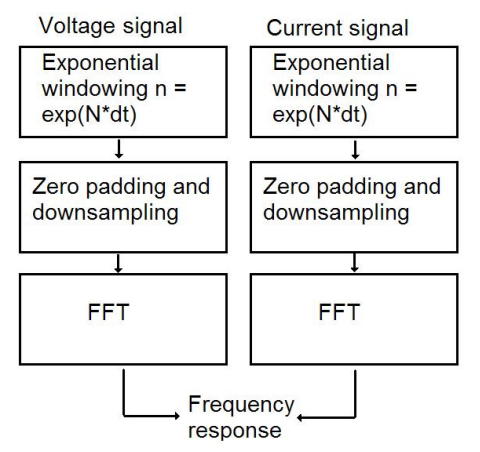

Fig. 1. Algorithm used to obtain the frequency response from the lightning impulse tests.

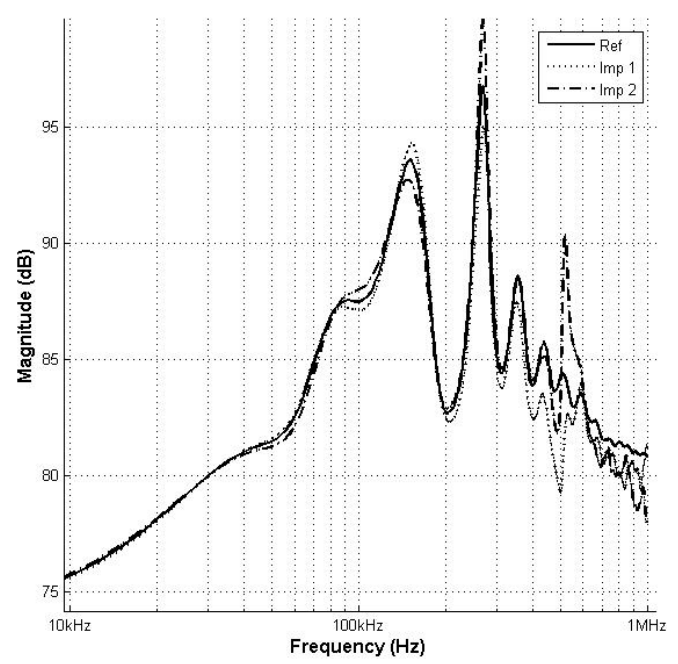

Fig. 2. Frequency response of the transformer under study determined by the application of two different impulses compared to the reference frequency response.

TABLE I

CORRELATION OF SEVERAL IMPULSE CASE 1 AND 2 SHOW THE CORRELATION BETWEEN UNFAULTED IMPULSES. CASE 3, 4 AND 5 CORRELATION BETWEEN FAULTED IMPULSES.

\begin{tabular}{|c|c|c|c|c|c|c|}
\hline \multirow{2}{*}{$\begin{array}{c}\text { Initial } \\
\text { Frequency }\end{array}$} & \multirow{2}{*}{$\begin{array}{c}\text { Final } \\
\text { Frequency }\end{array}$} & \multicolumn{5}{|c|}{ Correlation } \\
\cline { 3 - 7 } & & $\begin{array}{c}\text { Case } \\
1\end{array}$ & $\begin{array}{c}\text { Case } \\
2\end{array}$ & $\begin{array}{c}\text { Case } \\
3\end{array}$ & $\begin{array}{c}\text { Case } \\
4\end{array}$ & $\begin{array}{c}\text { Case } \\
5\end{array}$ \\
\hline $10 \mathrm{kHz}$ & $100 \mathrm{kHz}$ & 0.9999 & 0.9987 & 0.996 & 0.9973 & 0.9976 \\
$100 \mathrm{kHz}$ & $200 \mathrm{kHz}$ & 0.9992 & 0.9967 & 0.9947 & 0.9958 & 0.9975 \\
$200 \mathrm{kHz}$ & $300 \mathrm{kHz}$ & 0.9986 & 0.994 & 0.9738 & 0.9779 & 0.9627 \\
$300 \mathrm{kHz}$ & $400 \mathrm{kHz}$ & 0.9992 & 0.9997 & 0.9901 & 0.994 & 0.9942 \\
$400 \mathrm{kHz}$ & $500 \mathrm{kHz}$ & 0.9921 & 0.9962 & 0.9971 & 0.9696 & 0.9959 \\
\hline
\end{tabular}

In chopped wave impulses the repeatability of the frequency response obtained deteriorated at high frequency. This situation arises from the increased dynamic range of the current that rises to higher values due to larger $\mathrm{dV} / \mathrm{dt}$ present at the time of chopping. The use of a higher vertical resolution as in a 10 bit digitizer should solve the problem as is shown in [7]. A comparison of the frequency response obtained from the application of a full wave and that obtained from the application of a chopped wave was possible, the responses agreed up to $500 \mathrm{kHz}$ and good coherence and correlation was found between the responses. Even so with the use of the 
High Voltage generator repeatability was not assured.

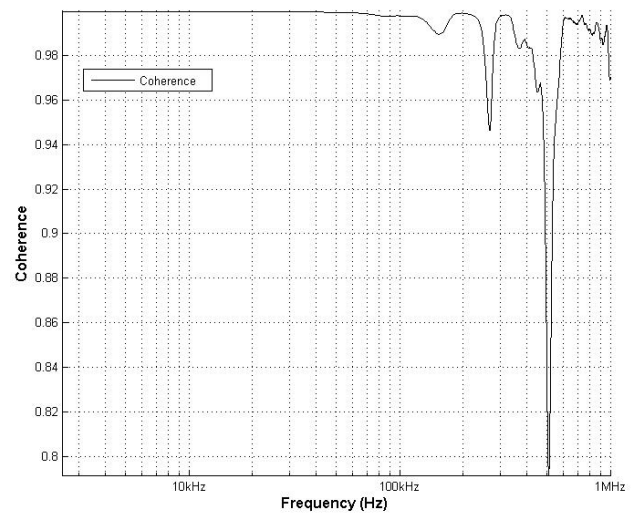

Fig. 3. Coherence function between the 3 measurements appearing in Fig. 2.

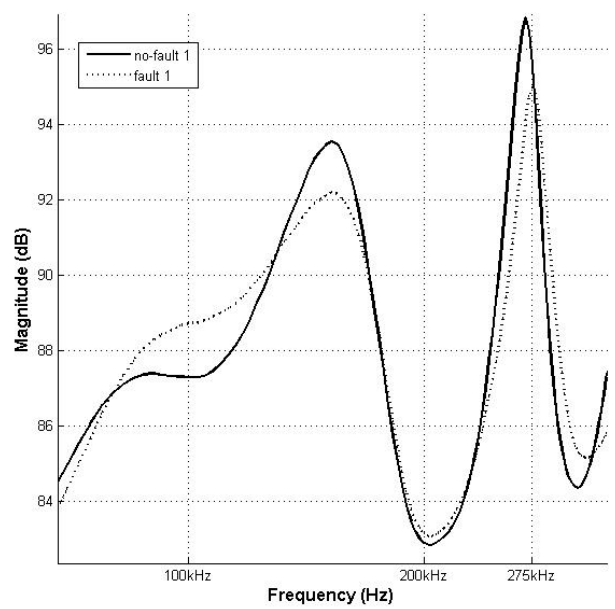

Fig. 4. Frequency response of faulted and non-faulted transformer obtained applying impulses with the repetitive surge generator.

\section{Final testing}

As in standard lightning impulse test calibration was performed using the repetitive surge generator. In this case the calibration included typical determination of the parameters used to obtain the desired wave shape and magnitude, but also verifying the frequency response of the system assuring reliable diagnosis. The maximum frequency reliable for diagnosis was set at $500 \mathrm{kHz}$ due to limitations on the coherence obtained and the minimum at $30 \mathrm{kHz}$ due to limitations on the toroidal current transformers at low frequency.

Several reduced (50\%BIL) impulse waves were applied. The standard connection was used, having all non tested windings grounded and measuring neutral current of the tested winding. Three types of fault where modeled: short circuit between middle winding to ground, short circuit between middle discs of the tested winding and insipient fault between middle discs of tested winding. The short circuit at middle winding to ground was clearly diagnosed by time record of the neutral current, so obtaining the frequency response was not necessary for diagnosis. The short circuit between the discs was not seen neither on voltage or neutral current records so the frequency response was obtained to determine diagnosis capability. In Fig. 5a the voltage record of the applied impulses in non-faulted and faulted condition are presented as shown in IEEE impulse guide [1], it can be seen that no difference is visible. In Fig. $5 b$ the neutral current record, is clear that no difference between non-faulted and faulted condition can be easily determined even knowing that the failure is present, so this case was chosen to verify the diagnosis capability of the methodology.

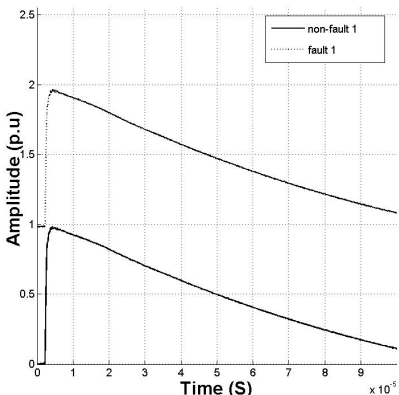

a)

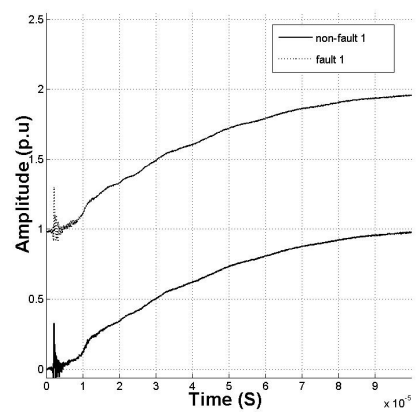

b)
Fig. 5. Applied voltage a) and neutral current b) of faulted and non-faulted transformer obtained applying impulses with the High Voltage generator.

In Fig. 6 the frequency response obtained for three different impulses in faulted and non-faulted condition show that there is an important discrepancy with the existence of failure but also that there are differences between measurements on the same condition. The calculation of the correlation and the use of tolerance bands solve this problem assuring proper diagnosis.

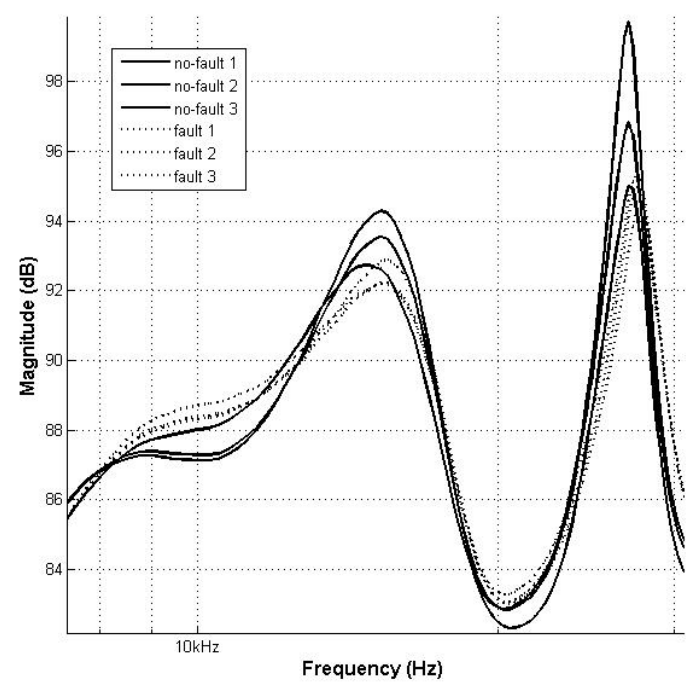

Fig. 6. Frequency Response obtained from several impulses applied in nonfaulted and faulted condition. 
The correlation between two measurements without any fault and the correlation between faulted and non-faulted test are shown in table 2 . The correlation function decrease in the frequency range between $100 \mathrm{kHz}$ and $250 \mathrm{kHz}$ only on the cases were there is a fault present.

TABLE II

CORRELATION OF SEVERAL IMPULSE CASE 1 AND 2 SHOW THE CORRELATION BETWEEN UNFAULTED IMPULSES. CASE 3, 4 AND 5 CORRELATION BETWEEN FAULTED IMPULSES.

\begin{tabular}{|c|c|c|c|c|c|c|}
\hline \multirow{2}{*}{$\begin{array}{c}\text { Initial } \\
\text { Frequency }\end{array}$} & \multirow{2}{*}{$\begin{array}{c}\text { Final } \\
\text { Frequency }\end{array}$} & $\begin{array}{c}\text { Case } \\
1\end{array}$ & $\begin{array}{c}\text { Case } \\
2\end{array}$ & $\begin{array}{c}\text { Case } \\
3\end{array}$ & $\begin{array}{c}\text { Case } \\
4\end{array}$ & $\begin{array}{c}\text { Case } \\
5\end{array}$ \\
\hline $10 \mathrm{kHz}$ & $100 \mathrm{kHz}$ & 0.9988 & 0.9962 & 0.9929 & 0.9914 & 0.9925 \\
$100 \mathrm{kHz}$ & $200 \mathrm{kHz}$ & 0.9986 & 0.9966 & 0.9004 & 0.9220 & 0.8894 \\
$200 \mathrm{kHz}$ & $300 \mathrm{kHz}$ & 0.9998 & 0.9997 & 0.9952 & 0.9933 & 0.9917 \\
$300 \mathrm{kHz}$ & $400 \mathrm{kHz}$ & 0.9997 & 0.9996 & 0.9966 & 0.9984 & 0.9966 \\
$400 \mathrm{kHz}$ & $500 \mathrm{kHz}$ & 0.9994 & 0.9987 & 0.9990 & 0.9964 & 0.9990 \\
\hline
\end{tabular}

The use of tolerance band is illustrated in Fig. 7a and Fig. 7b. A nominal SNR of $40 \mathrm{~dB}$ is obtained for the voltage from its frequency content; and a SNR of $38 \mathrm{~dB}$ is obtained for the current. In Fig. 7a two non-faulted measurements with their respective tolerance bands are shown, it can be seen how the bands ensure that the differences obtained can be attributed to noise in the voltage and current records. In Fig. $7 \mathrm{~b}$ tolerance bands between faulted and non-faulted frequency responses are shown, and it can be seen how their tolerance bands do not overlap so the differences between them can not be attributed to noise in the measurement record. This way the tolerance bands ensure giving the proper diagnosis by taking into consideration the presence of noise in the measurement records.

During the realization of tests it was noted that the frequency response obtained from the repetitive surge generator was different from that obtained using the $2.4 \mathrm{MV}$ impulse generator. Final tests were performed using a Modular High Voltage Kit to ensure the proper frequency response was obtained. The responses of the repetitive surge generator and the High Voltage Kit are identical and that of the $2.4 \mathrm{MV}$ generator differ in a considerable manner. This differences where determined to be caused by the damped response of the high voltage divider used, and the different circuit topology used by the 2.4MV High Voltage generator.

\section{PlatForm}

The platform developed consist of the frequency response calibrated measuring devices, the oscilloscope used for impulse voltage and neutral current measurement, and a graphical user interface developed in MATLAB. The system was developed as part of a master degree thesis for the Simón Bolivar University [48]. The graphical user interface allow for comparison of time domain curves and frequency domain response, obtaining the tolerance band of measurement, filtering, windowing, automatic compensation of vertical and horizontal offset, divider ratios, amplitude again, exporting graphics and report generator.

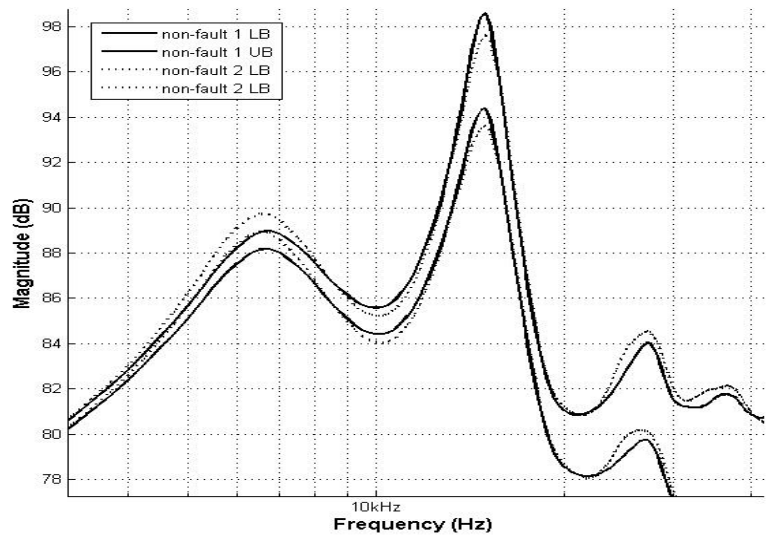

a)

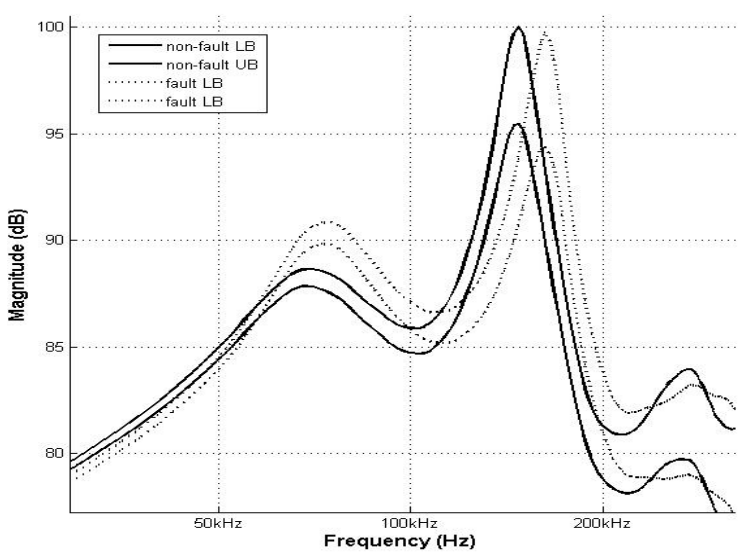

b)

Fig. 7. Tolerance bands of two frequency responses. Non-faulted condition a), and faulted condition $b$ ).

\section{CONCLUSION}

A front-end application for the MATLAB FFT tool has been developed to obtain the frequency response on a transformer winding from voltage and neutral current measured during lightning impulse test. The difficulties arising from the use of 8 Bit digitizer have been addressees by mean of tolerance band and coherence function. The diagnosis process has been updated using a correlation function as a numeric indicator of faults. The system has been tested using the actual equipment used during real live testing.

\section{REFERENCES}

[1] ANSI/IEEE Std C57.98-1993. Guide for Transformer Impulse Test.

[2] K. Karsai, D. Kerényi, L. Kiss, "Large Power Transformers", Akadémiai kiadó, Budapest 1987.

[3] IEEE Std. C57.12.00-2000 Standard General Requirements for LiquidImmersed Distribution, Power and Regulating Transformers.

[4] IEC 76-3 1980 Part 3 Insulation levels and dielectric test.

[5] R. Malewski, B. Poulin. "Impulse testing of power transformers Using the Transfer Function Method". IEEE Trans. Power Delivery, Vol. 3, No 2, Abril de 1988.

[6] C.G.A. Koreman, "Improvements in transformer testing through the use of the transfer function”, 5th ISH, Braunschweig, 1987. 
[7] Hanique, E. "A Transfer Function is a reliable Tool for Comparison of Full- and Chopped Lightning Impulse Tests". IEEE Trans. Power Delivery, Vol. 9, No. 3, July 1994

[8] E.P. Dick, C.C. Erven. "Transformer Diagnostic Testing by Frequency Response Analysis". IEEE Transactions on Power Apparatus and Systems, Vol. 1, № 6, pp 2144-2153, Noviembre/Diciembre de 1978.

[9] Xu, D.K.; Fu, C.Z.; Li, Y.M.; "Application of artificial neural network to the detection of the transformer winding deformation". Eleventh International Symposium on High Voltage Engineering, 1999. (Conf Publ. No. 467), Volume: 5, 23-27 Aug. 1999. Page(s): 220 -223 vol.5

[10] T. Liebfried, K. Feser. "Monitoring of Power Transformers using the Transfer Function Method." IEEE Transactions on Power Delivery, Vol. 14, No 4, pp 1333-1341, October 1999.

[11] J. Bak-Jensen, B. Bak-Jensen, S.D. Mikkelsen. "Detection of Faults and Ageing phenomena in Transformers by Transfer Functions". IEEE Transactions on Power Delivery, Vol. 10, $\mathrm{N}^{\mathrm{o}}$ 1,pp 308-314, January 1995.

[12] E. Da Silva, J. Ramírez, M. Martínez, J. Rodríguez, S. Dávila, B. Valecillos, "Caracterización de la Corriente de Fuga en el Diagnostico de Descargadores de Sobretensiones de Carburo de Silicio", ALTAE 05, Panamá, Panamá, Julio 26-30, 2005.

[13] Ramírez J., Davila S. Valecillos B. Martínez M. Rodríguez J.C. Da silva E. Velazco J. "Models of Grounding Systems under Lightning Discharges. Simple Electrode Configurations" ICLP, Procceedings Volume I, Avignon, France September 13-16 2004

[14] M. Steurer, W. Hribernik, J. H. Brunke, "Calculating the Transient Recovery Voltage Associated With Clearing Transformer Determined Faults by Means of Freaquency Response Analysis", IEEE Trans. Power Delivery, Vol. 19, No. 1, January 2004.

[15] T. O. Bialek, "Evaluation and Modelling of High Voltage Cable Insulation Using a High Voltage Impulse" PhD Dissertation, Mississippi State University, February 2005.

[16] L. V. Bewley, "Traveling Waves on Transmission Systems", Second Edition, Dover

[17] A.C. Franklin, D.P. Franklin "The J\&P transformer book" 11th edition, Butterworths. 1983

[18] IEEE Std. C57.138-1998. Recommended Practice for Routine Impulse Test for Distribution Transformers.

[19] IEEE Std. C57.12.90.1999 IEEE Standard Test Code for LiquidImmersed Distribution, Power and Regulating Transformers.

[20] IEC 761980 Power transformers.

[21] IEEE Std 4-1995. Standard Techniques for High-Voltage Testing.

[22] IEC 60-1 1989 High Voltage Test Techniques- Part 1: General definitions and test requirements.

[23] IEC 7221982 Guide to the lightning impulse and switching impulse testing of power transformers and reactors.

[24] A.V. Oppenheim, A.S. Willsky, I.T. Young "Signals and Systems" Prentice-Hall International 1983. pp 212-214.

[25] G.G. Karady M. Reta-Hernandez F. Amarh G. McCulla. "Improved Technique for Fault Detection Sensitivity in Transformer Impulse Test" 0-7803-6420-1/00/\$10.00 (c) 2000 IEEE.

[26] I.R. McComb, J. Kuffel, R. Malewski, K. Shon. "Qualifying An Impulse Test Digitizer for Measurement in HV Impulse Test". IEEE Trans. Power Delivery, Vol. 5, № 3, pp 1256-1265, July 1990.

[27] J. Kuffel, R. Malewski. "Modelling of the Dynamic Performance of Transient Recorders Used for High Voltage Impulse Tests". IEEE Trans. Power Delivery, Vol. 6, № 2, pp 507-515, April 1991.

[28] IEEE Std 1122-1998. IEEE Standard for Digital Recorders for Measurements in High-Voltage Impulse Tests.

[29] R. Malewski: A. Claudi. Ch. Josepliy: St. Jud: "Checking electromagnetic compatibility of a HV impulse measuring circuit with coherence Functions": ERA Technology Conference H.V. Measurements and Calibration; Arnhem. 1994.

[30] Stoica, P., and R. Moses. "Introduction to Spectral Analysis." Upper Saddle River, NJ: Prentice-Hall, 1997. Pgs. 61-64.

[31] Larry Coffeen, Jeffrey Britton, Johannes Rickman. "A new technique to detect winding displacements in power transformers using frequency response analysis", IEEE Bologna PowerTech Conference, June 23-26, Bologna, Italy. 2003.

[32] IEEE PC57.149, "Guide for the Application and Interpretation of Frequency Response Analysis for Oil Immersed Transformers,"
[33] S. Birlasekaran, Fred Fetherston. "Off/On-Line FRA Condition Monitoring Technique for Power Transformers". IEEE Power Engineering Review, pp 54-56, Agosto de 1999.

[34] T. Leibfried K. Fesser. "Online Monitoring of Transformers by Means of the Transfer Function Method". CNF. Intenational Symposium on Electrical Insulation Pittburgh P.A. USA June 5-8 1994.

[35] T. Leibfried K. Fesser. "Offline-Online Monitoring of Power Transformers Using Transfer Function Methods". Intenational Symposium on Electrical Insulation, Quebec Canada June 16-19 1996.

[36] S.A. Ryder. "Experimental investigations of the repeatability of FRA Measurements." 2002 International Conference of Doble Clients Papers.

[37] S. A. Ryder. "Methods for Comparing Frequency Response Analysis Measurements." Conference Record of the 2002 IEEE International Symposium on Electrical Insulation, Boston, MA USA, April $7-$ 10,2002

[38] J.A.S.B. Jayasinghe, Z.D. Wang, P.N. Jarman, A.W. Darwin. "Investigations on Sensitivity of FRA Technique in Diagnosis of Transformer Winding Deformations". IEEE, ISEI Indianapolis USA, 19-22 September 2004.

[39] S.A. Ryder. "Transformer diagnosis Using Frequency Response Analysis: Results from Faults Simulations". 0-7803-7519-X/02/\$17.00 (C) 2002 IEEE.

[40] S. M. Islam, "Detection of Shorted Turns and Winding Movements on Large Power Transformers using Frequency Response Analysis" 07803-5935-6/00/\$10.00 (c) 2000 IEEE.

[41] A. De, N. Chatterjee, "A Fuzzy ARTMAP Fault Classifier for Impulse Testing of Power Transformers" IEEE Transactions on Dielectrics and Electrical Insulation Vol. 11, No. 6; December 2004.

[42] J. Pleite, E. Olías, A. Barrado, A. Lazáro J. Vázquez. "Transformer Modeling for FRA Techniques." Transmission and Distribution Conference and Exhibition 2002: Asia Pacific. IEEE/PES, Volume: 1, 6-10 Oct. 2002. Page(s): 317 -321 vol.1

[43] E. Rahimpour, J. Christian, K. Feser, H. Mohseni. "Transfer Function Method to Diagnose Axial Displacement and Radial Deformation of Transformer Windings." IEEE Trans. Power Delivery Vol. 18, Nº. 2, April 2003.

[44] J. Christian and K. Feser, "Procedures for Detecting Winding Displacements in Power Transformers by the Transfer Function Method.”, IEEE Trans on Power Delivery, Vol. 19, N. 1, January 2004.

[45] J. Hällström, M-L. Pykälä, "Evaluation of Power Transformer Transfer Function from Impulse Test Records" Nordic Insulation Symposium, Tampere, June 11-13, 2003

[46] D. Donnelly B. Rust, "The Fast Fourier Transform For Experimentalists, Part I: Concepts", copublished IEEE CS and the AIP, Computing Science and Engineering, pp 80-88 March-April 2005.

[47] R.W. Ramirez, "The FFT Fundamentals and Concepts" Prentice-Hall 1985.

[48] B. Valecillos "Sistema de evaluación de resultados para los ensayos de impulso a transformadores", Spanish, M.Sc. dissertation, Dept. of energy transport and conversion, University Simon Bolivar, Caracas, Venezuela, 2006.

\section{BIOGRAPHIES}

Baudilio Valecillos, was born in Caracas, Venezuela 1977. He received the Ing. Electrical Engineering and M.Sc. degree from the University Simón Bolívar in 2001 and 2006 respectively. Currently, he is a Ph.D. student at the University Carlos III of Madrid, in Spain. He was an assistant at University Simón Bolívar for two years and has been an assistant professor at University Carlos III of Madrid for two years. His research interests include transformer diagnosis by dielectric response measurement, Frequency Response Analysis, and finite element modelling.

Jorge Ramírez, (S'82-M'83-SM'99).He had been graduated in Electrical Engineering and received MSc. degree in Electrical Engineering from the Simon Bolivar University in 1983 and 1985, respectively. He is a Professor of Electrical Engineering at the Simon Bolivar University. He is also currently Director of the High Voltage Laboratory of the Simon Bolivar University. His research interests are high voltage measurements and test techniques, electrical insulation and electromagnetic transients. 